\title{
Remediation of soils polluted with lindane using surfactant- aided soil washing and electrochemical oxidation
}

\author{
M. Muñoz-Morales, M. Braojos, C. Sáez, P. Cañizares, M.A. Rodrigo* \\ Department of Chemical Engineering, Faculty of Chemical Sciences and Technologies, \\ University of Castilla-La Mancha, Campus Universitario s/n, 13005 Ciudad Real, Spain
}

\begin{abstract}
In this work the complete treatment of soil spiked with lindane is studied using surfactantaided soil-washing (SASW) to exhaust lindane from soil and electrolysis with diamond anodes to mineralize lindane from the soil washing fluid (SWF) waste. Results demonstrated that this technological approach is efficient and allow to remove this hazardous pollutant from soil. They also pointed out the significance of the ratio surfactant/soil in the efficiency of the SASW process and in the performance of the later electrolysis used to mineralize the pollutant. Larger values of this parameter lead to effluents that undergo a very efficient treatment which allows the depletion of lindane for applied charges lower than $15 \mathrm{Ah} \mathrm{L}^{-1}$ and the recovery of more than $70 \%$ of the surfactant for the regeneration of the SWF.
\end{abstract}

\section{Keywords}

Surfactant-aided; soil washing; lindane; electrolysis; diamond

*author to whom all correspondence should be addressed: manuel.rodrigo@uclm.es 


\section{Highlights}

- Lindane can be drained from soil by SASW using high surfactant/soil ratios

- Quality of the effluent of SASW depends strongly on the surfactant/soil ratio

- Lindane can be oxidized from SASW wastes by electrolysis with diamond anodes

- SDS is oxidized more slowly than lindane opening the possibility of re-use of the SWF 


\section{Introduction}

Removal of hazardous species from soils is an environmental priority, in order to avoid the further magnification of the problem with the later pollution of water reservoirs [1-3]. Electrochemical technologies tailored to reach this target are gaining special attention in the recent years [4-6]. Among them, the combination of surfactant-aided soil-washing (SASW) and advanced electrochemical oxidation processes (EAOP) have been the objectives of many research works[7-10] including several recent papers of our group [11-16], in which it has been pointed out a rather good performance with the exhaustion of the target compounds from both the soil matrix and the waste soil washing fluid (SWF). With respect to SASW, great effort has been made in the recent years to understand the mechanisms involved and to reach high performance in the removal of pollutants [1721], and even to add reagents that can treat onsite the pollutant [22]. Among the advanced oxidation processes, electrolysis with diamond anodes has reached a special level of interest, because of the outstanding performance of the technology as compared with other Advanced Oxidation Processes (AOPs) [23, 24].

$\gamma$-Hexachlorocyclohexane (or lindane) is a very controversial but effective pesticide [25]. Nowadays, it is banned as agricultural pesticide in the numerous group of countries that signed the Stockholm Convention on Persistent Organic Pollutants. However, it is still produced and used as a pharmaceutical product for the treatment of lice and scabies in such countries and as an effective pesticide in non-signing countries. Both, health and environmental considerations are behind its inclusion in the Stockholm Convention. Regarding its effects on human health, it is known to harm the nervous system and suspected to be carcinogen. Regarding environment, lindane has a great persistence (large lifetime) and the potentiality to be transported at long distances and to be accumulated in the food chain. Despite being banned in many countries, it has been used massively for 
more than 50 years all around the World. Even in countries in which it is banned, there are many polluted sites [26], which cause great social alarm, being a very representative example the case of the pollution produced by an already closed down lindanemanufacturing factory in the region of Sabiñañigo in the North of Spain [27].

The removal of lindane has been faced by several authors, using not only biological technologies [25, 28] but also different types of AOPs, including hydrogen peroxide [29] and activated peroxymonosulfate [30]. The treatment of this hazardous pollutant can also be obtained by reductive dehalogenation and recent works, in which Zerovalent Iron (ZVI) is used as reductive agent, are of a great interest [31,32]. Regarding the application of electrolysis, it is important to note that more attention has been paid to the cathodic dechlorination [33-36] than to the mineralization of the lindane, which has been faced by mediated oxidation with highly powerful inorganic cationic oxidants [37]. This dechlorination is highly efficient and, even, it was proposed for being combined with biological treatment in a pioneering manuscript published more than forty years ago [38]. Therefore, the objective and main novelty of this work was to study the complete treatment of soil spiked with lindane using (1) SASW with sodium dodecyl sulfate (SDS) to exhaust lindane from soil and (2) electrolysis with diamond anodes to mineralize lindane from the SWF waste. To do this, firstly the optimum ratio SDS/soil required to extract the maximum amount of lindane from the spiked soil is evaluated, paying attention to the influence of the washing conditions and SDS concentration in the SWF generated. In a second step, the study is focused on the destruction of the lindane contained in the SWF by electrolysis, evaluating the role of the SDS/soil ratio in the treatability of the effluents generated by the SASW process.

\section{Materials and methods}


Chemicals. Lindane $\left(\mathrm{C}_{6} \mathrm{H}_{6} \mathrm{Cl}_{6}, 97 \%\right)$, Sodium Dodecyl Sulfate (SDS) (used as solubilizing agent) and Hexane (Sigma Aldrich, Spain) were analytical grade and used as received. Ethyl Acetate high pure were obtained from Sigma Aldrich and used for GCECD. Methanol was obtained from VWR. Double deionized water (Millipore Milli-Q System, resistivity: $18.2 \mathrm{M} \Omega \mathrm{cm}$ at $25^{\circ} \mathrm{C}$ ) was used to prepare the $\mathrm{SWF}$.

Analytical techniques. To determine lindane concentration in the liquid phase, an $\mathrm{L}-\mathrm{L}$ extraction process was used before the analysis. This process was carried out in separator flasks of $10 \mathrm{~mL}$, using ethyl acetate as extraction solvent (ratio lindane solution/solvent $=1 \mathrm{v} / \mathrm{v}$ is required to extract $100 \%$ of lindane contained in the aqueous phase). After that, all samples extracted from electrolyzed solution were filtered with $0.25 \mu \mathrm{m}$ nylon filters before analysis by Gas Chromatography-Electron Capture Detector (GC ECD) (Thermo Fisher Scientific) using a TG-5MS capillary column (30m x $0.25 \mathrm{~mm}$ $0.25 \mathrm{~mm})$ and ${ }^{63} \mathrm{Ni}$ micro-electron capture detector, a split/splitless inyector and ChromCard Software. Under the conditions used, the quantification limit of the GC ECD was $0.02 \mathrm{mg} \mathrm{L}^{-1}$. The flow rate of gas $\mathrm{He}$ was $1.0 \mathrm{~mL} \mathrm{~min}{ }^{-1}$. The temperature of the injector was $210^{\circ} \mathrm{C}$. The total organic carbon (TOC) concentration was monitored using a Multi N/C 3100 Analytik Jena. Measurements of $\mathrm{pH}$ and conductivity were carried out using a CRISON pH25+ and CRISON CM35+. The colorimetric method used to determine the concentration of the SDS surfactant has been elsewhere [39]. The anions present in the target wastewater were characterized using ion chromatography by means of a Shimadzu LC-20A system.

Preparation of polluted soil and soil-washing fluid (SWF). The soil used in this study was from a quarry located in Toledo (Spain). This soil is characterized by its inertness, low hydraulic conductivity $\left(10^{-8} \mathrm{~cm} \mathrm{~s}^{-1}\right)$ and lack of organic content. Samples of polluted soil were prepared by dissolving lindane $(0.2 \mathrm{mg})$ in hexane $(100 \mathrm{~mL})$ and then by mixing 
this lindane/hexane solution with soil. The soil-hexane-lindane mixture was stirred and blended homogeneously. The spiked clay was aerated for 1 day, in order to promote evaporation of the hexane. The resulting lindane concentration in the soil was around 100 $\mathrm{mg} \mathrm{kg}{ }^{-1}$ of soil. The preparation of SASW effluents was carried out in a stirred batch tank as described elsewhere $[11,13]$. Low-permeability soil (amount ranging from 100 to 400 g) polluted with $100 \mathrm{mg}$ lindane $\mathrm{kg}^{-1}$ of soil and $1.0 \mathrm{~L}$ of SWF (concentration ranging from 100 to $20000 \mathrm{mg} \mathrm{L}^{-1}$ ) were mixed in the reactor for $24 \mathrm{~h}$. Then, the same tank acted as a settler (for $24 \mathrm{~h}$ ) to split up the soil from the washing effluent. Both magnetic and paddle stirrers were used with stirring gradients of velocity $(\mathrm{G})$ of 4900 in the case of the magnetic stirrer and $3160 \mathrm{~s}^{-1}$ in the case of the paddle stirrer, in order to evaluate harsh and soft mixing conditions in the SASW.

Experimental setup. The SASW effluents were treated by electrolysis with diamond anodes using a bench-scale electrochemical setup described elsewhere [40]. Boron doped diamond (BDD) and stainless steel electrodes were used as anode and cathode, respectively. Both electrodes were circular (100 mm diameter) covering a geometric area of $78 \mathrm{~cm}^{2}$. The characteristics of the BDD used were: $100 \mathrm{~m} \Omega$ of resistivity of the $\mathrm{Si}$ wafers, 2-3 $\mu \mathrm{m}$ of BDD-coating thickness, $500 \mathrm{ppm}$ of boron concentration and 250 of $\mathrm{sp}^{3} / \mathrm{sp}^{2}$ ratio. The SASW effluent was stored in a thermo-regulated glass tank $(1 \mathrm{~L})$ and circulated through the cell using a peristaltic pump at a flow rate of $60 \mathrm{Lh}^{-1}$. The electrical current was applied using a Delta Electronika ES030 (0-30 V, 0-10 A). The electrolysis was carried out galvanostatically at $50 \mathrm{~mA} \mathrm{~cm}^{-2}$. Prior to use in galvanostatic electrolysis assays, the electrode was polarized for 10 min in a $0.035 \mathrm{M} \mathrm{Na}_{2} \mathrm{SO}_{4}$ solution at $15 \mathrm{~mA} \mathrm{~cm}{ }^{-2}$ to remove any impurities from its surface. Temperature was kept constant $\left(25^{\circ} \mathrm{C}\right)$ by means of a thermos-regulated water bath. 


\section{Results and discussion}

The first step for the treatment of soils polluted with lindane by the combined technologies proposed in this work, is the application of SASW process [41, 42]. In this case, SDS was selected as surfactant and different amounts were dosed in order to extract the pollutant. Because of the existence problems of reproducibility, found in previous experiments, and after detecting that mixing conditions had a paramount significance on results, two different mixing conditions were tested and extraction of lindane for both settings is shown in Figure 1. In the first series of tests, the velocity gradient applied was $4900 \mathrm{~s}^{-1}$ with a magnetic stirrer while in the second this values was only of $3160 \mathrm{~s}^{-1}$ and a paddle stirrer was used. The stirring in the case of the magnetic stirrer was not only more powerful because of the use of a higher G, but also because due to its position it moved up the soil from the bottom of the tank producing a vortex and great turbulence, observable just at naked eye.

As it can be seen in Figure 1, in using the right dose and harsh mixing conditions, it is possible to exhaust this hazardous pollutant from soil and to transfer it to the flushing fluid completely. This efficient removal of the lowly hydro-soluble pollutant from soil was expected according to the results shown in previous works of our group [11-13, 43], for which the removal of atrazine and oxyfluorfen was studied. In those cases, the optimum ratio SDS/soil was $0.08 \mathrm{mg} / \mathrm{g}$, which was similar to the one required for lindane. As pointed out before, efficiency of the process is not only limited by the dose of surfactant added but also for the mixing conditions, because when mixing conditions are not intense enough, the formation of micelles is not favored. 


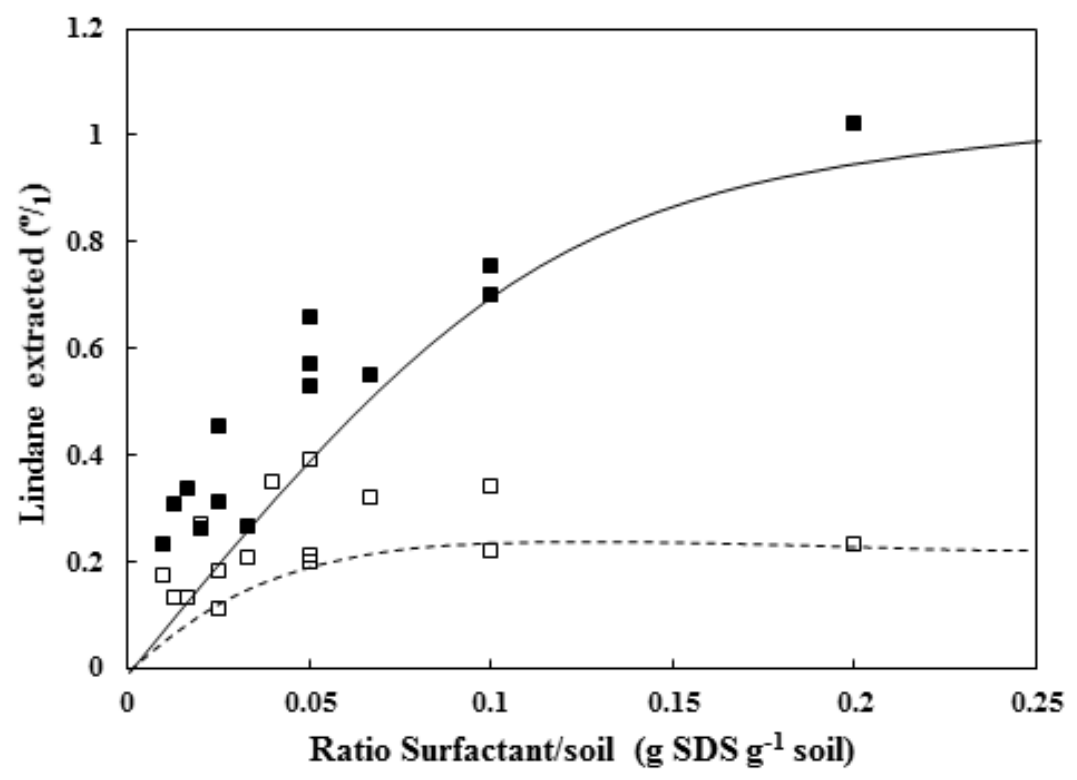

Figure 1. Percentage of lindane extracted from soil by the surfactant-aided soil washing process using different ratios surfactant soil under harsh (ם) and soft ( $\square$ ) mixing conditions.

These results confirm SASW as a very efficient technology to exhaust hazardous pollutants from soil and SDS as a highly recommended surfactant for this target, when the solubility of the pollutant in water is low, as it was also previously demonstrated for hydrocarbons $[16,44]$. At this point, it is important to take into account that after the last sedimentation stage of the SASW process, three phases can be clearly observed: a clarified liquid in the top, the washed soil in the bottom and a turbid interphase between both phases. In Figure 2, it is shown how lindane is distributed between both liquid phases and, for the sake of clarity, it is also included a picture in order to illustrate how they are distributed. It can be seen how the concentration of the SDS in the raw soil washing fluid influences the amount of lindane contained after the SASW process. The higher this concentration, the higher is the percentage of lindane extracted for the same ratio SWF /soil in both the interphase and the clarified liquid. It can also be seen that when large volumes of SWF are applied, the amount contained in the turbid interphase is much lower 
and opposite, the percentage contained in the clarified liquid increases almost linearly. It is in this range of surfactant/soil ratios where the most important differences were found between applying harsh and soft mixing conditions. Hence, these differences may be explained in terms of the impact of this turbid interphase in the overall washing process.

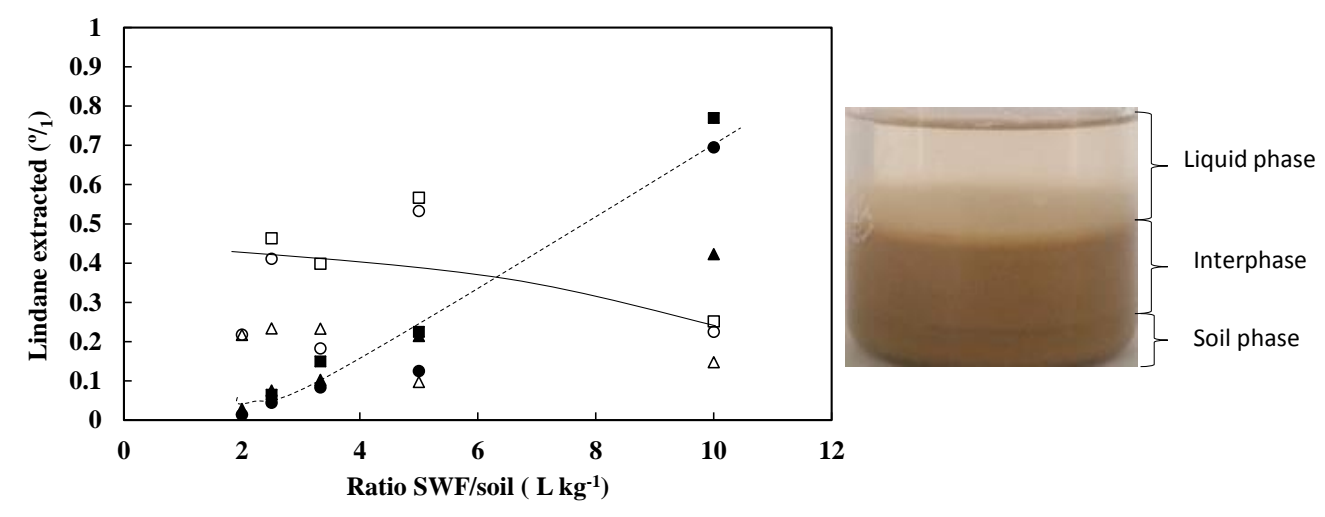

Figure 2. Distribution of lindane in the clarified liquid and in the interphase formed after the application of the SASW process. Concentration of SDS in the SWF used for the SASW: $\Delta 5 \mathrm{~g} \mathrm{~L}^{-1}$; $10 \mathrm{~g} \mathrm{~L}^{-1}$; $\mathbf{\square} 20 \mathrm{mg} \mathrm{L}^{-1}$. Full points: clarified liquid; Empty points interphase. Picture in the right illustrates the three phases formed with the application of the soil washing process

After the SASW, the SWF becomes a highly polluted wastewater, which does not only contain the pollutant extracted but also the surplus surfactant not retained into the treated soil. It has to be taken into account that the doses of SDS required to remove the lindane are pretty large and, hence, the waste flushing fluid will contain a very high concentration of this organic, which would become a handicap for an efficient treatment. Thus, as it can be seen in Figure 3, where the amounts of lindane and SDS contained in the resulting liquid waste are shown, lindane and SDS amounts increase with the ratio SDS/soil applied in the SASW. 


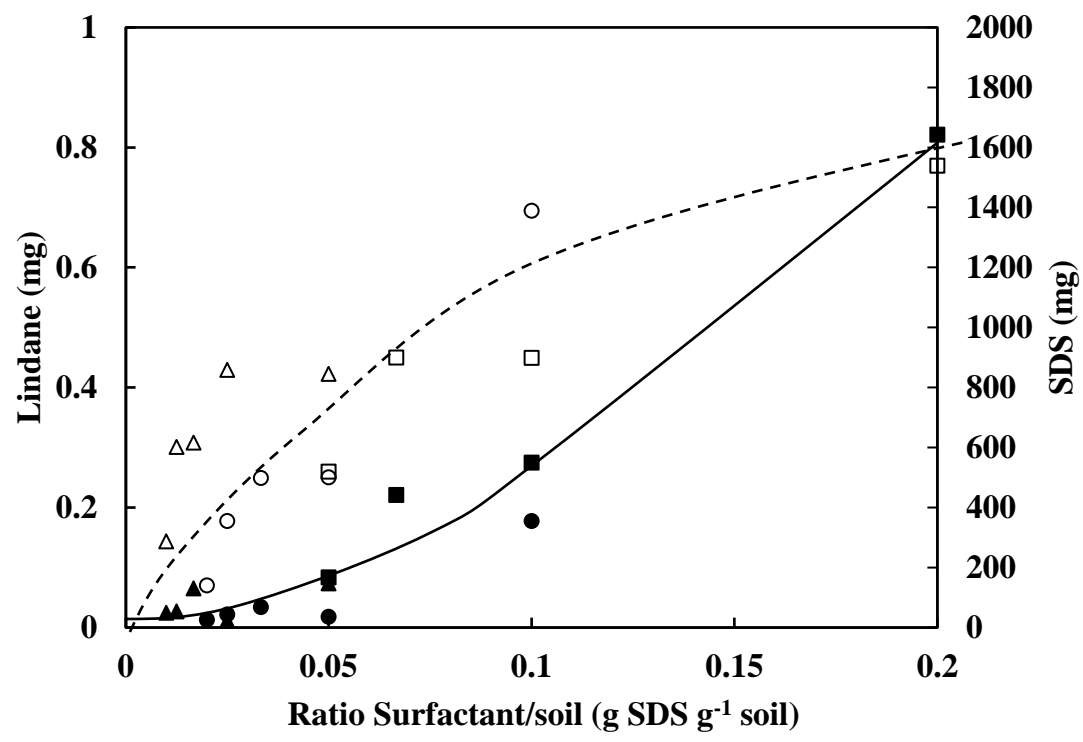

Figure 3. Amounts of lindane (empty symbols) and SDS (full symbols) extracted by the SWF during the treatment of soil polluted with $100 \mathrm{mg} \mathrm{kg}^{-1}$ of lindane at different SDS/soil ratios. Concentration of SDS in the raw SWF: $\boldsymbol{\Delta} 5.0 \mathrm{~g} \mathrm{~L}^{-1} ; \bullet 10 \mathrm{~g} \mathrm{~L}^{-1} ; \mathbf{\square} 20 \mathrm{~g}$ $\mathrm{L}^{-1}$

Obviously, the amount of both species cannot be compared (note that they are in different $y$-axis) because the surfactant is contained in a concentration which is 3 log-units above the organo-chlorinated pollutant. This will explain the high TOC of these effluents, which is not directly associated to the hazardousness of the lindane contained the wastewater (which in fact is a rather low concentration) but to the presence of the necessary amounts of surfactants required to remove the lindane. Dispersion in data indicates that this extraction is not a simple process and it can be influenced by many parameters, being the most important the concentration of the SDS in the raw soil-flushing fluid used. Again, the turbid interphase formed after the SASW process seems to play an important role and this is reflected in Figure 4, where it is shown the distribution of SDS in the soil, liquid clarified phase and turbid interphase for different ratios SDS/soil and different initial concentration of the SWF. 


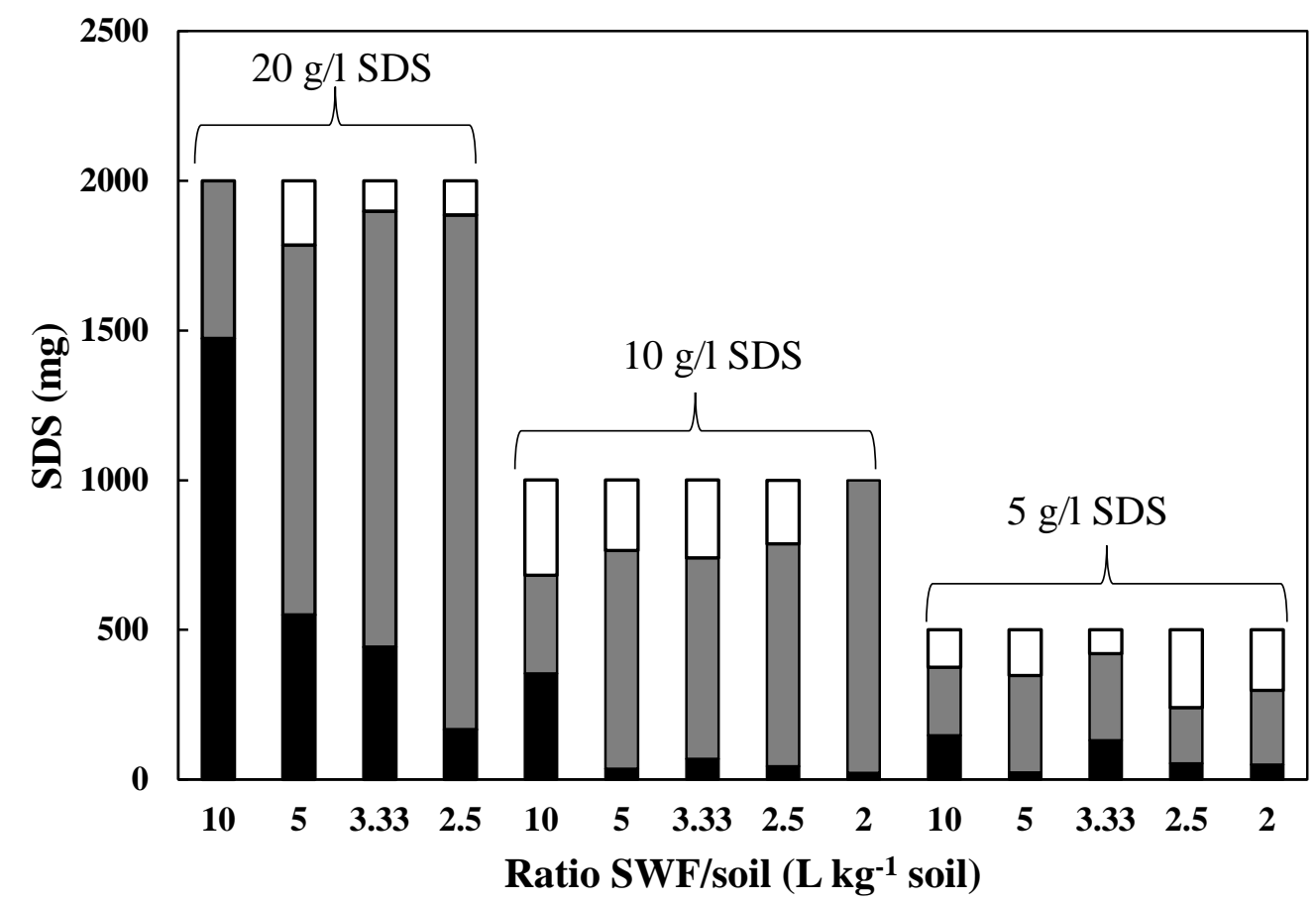

Figure 4. SDS distribution after the application of the SASW process among the soil ( $\square$ ), turbid interphase $(\square)$ and clarified liquid $(\square)$ during the treatment of soil polluted with $100 \mathrm{mg} \mathrm{kg}^{-1}$ of lindane at different SDS/soil ratios. Concentration of SDS in the raw SWF: $5.0 \mathrm{~g} \mathrm{~L}^{-1} ; 10 \mathrm{~g} \mathrm{~L}^{-1} ; 20 \mathrm{~g} \mathrm{~L}^{-1}$

As it can be observed, the amount of SDS contained in the interphase decreases with the ratio volume of SWF used/ mass of soil treated while it increases in the clarified liquid phase. Soil retains small amounts of SDS which do not seem to be related to the concentration of SDS in the SWF or to the dose of this fluid applied in the SASW process. At this point, not only the concentration of chemicals is important but also it is important to know how these species are aggregated into micelles. Figure 5 shows for the clarified liquid and for the interphase, the average particle size (50\%) and the limits of the 10 and $90 \%$ which, as it may be observed, are very narrow, in particular if they are compared with the variation of the mean size of the micelles with the ratio SDS/soil. Regarding this variation, the average size of the particles changes in almost a linear way with the ratio 
SDS/soil in the clarified liquid and it is maintained in a value slightly below $20 \mu \mathrm{m}$ in the interphase. This constant value observed in the interphase, and for low SDS/soil ratios, corresponds to the size of the soil particles, which are contained in large amounts as the samples did not undergo any type of filtering in these tests.

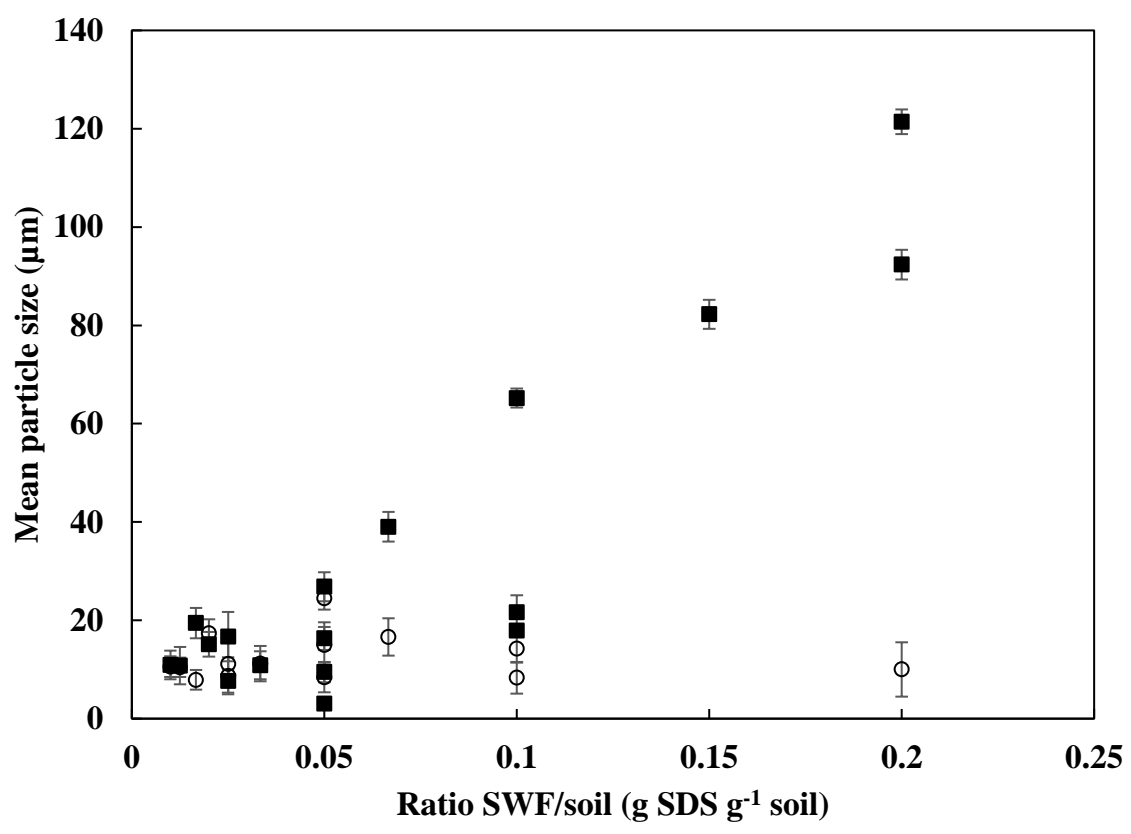

Figure 5. Particle size distribution in the two phases of SWFs: (ם) clarified liquid, (O) turbid interphase.

Once the separation of the lindane from the soil has been evaluated, the next step in the development of the combined treatment technology is the destruction of the lindane contained in the waste soil-washing fluid by electrolysis. To study this remediation, four different wastes were electrolysed. Each of then was obtained by treating the soil with a different SDS/soil ratio, ranging from 0.05 to $0.20 \mathrm{mg} \mathrm{g}^{-1}$ by mixing different amounts of a $20 \mathrm{mg} \mathrm{L}^{-1}$ solution of SDS with soil. Variation of lindane, TOC and concentration of the lone intermediate detected by GC ECD (operated under the conditions shown in the Materials and Method section) are shown in Figure 6. 

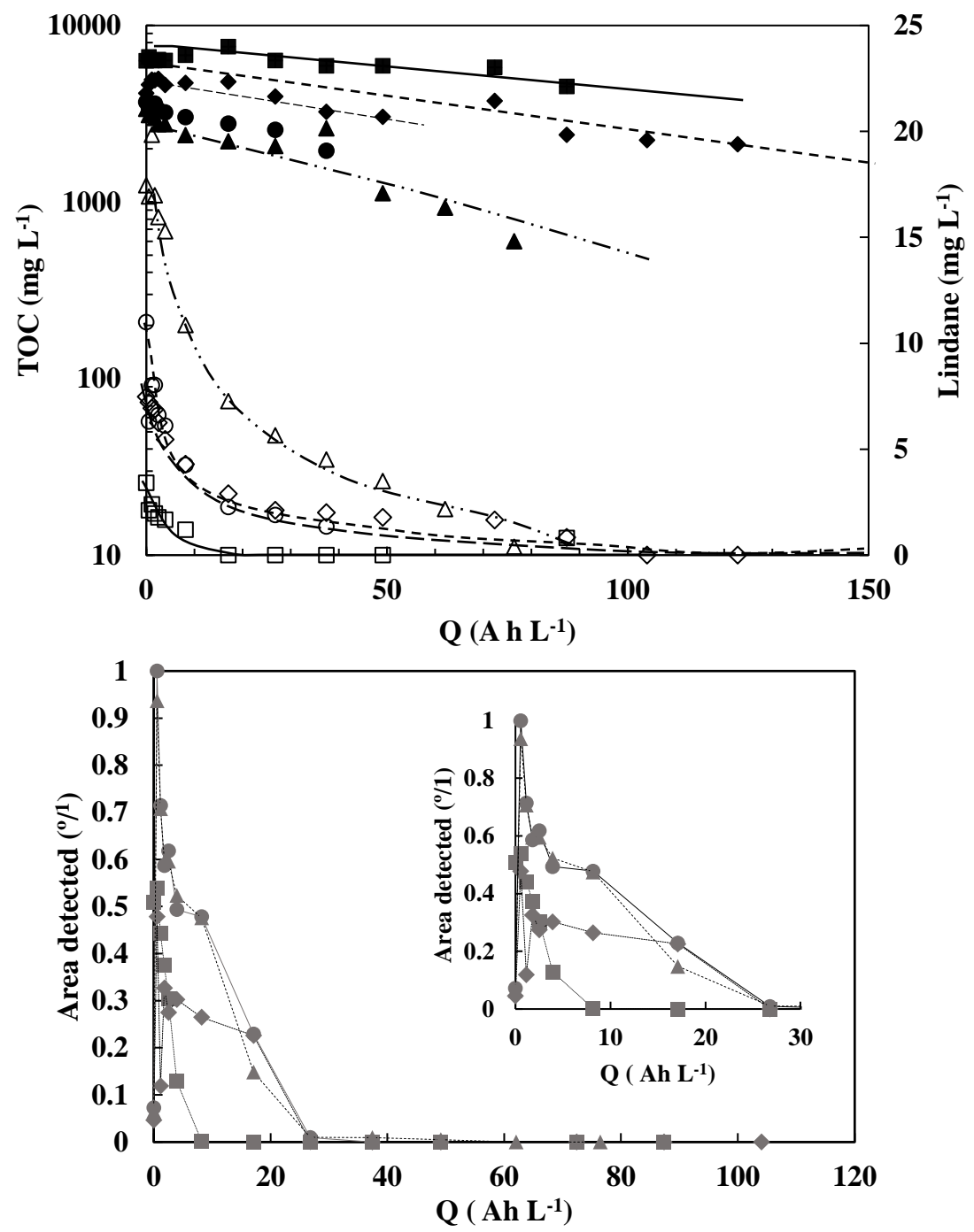

Figure 6. Removal of Lindane (empty symbols), intermediates (grey symbol) and TOC (full symbols) during the electrolysis of soil washing effluents carried out at 0.20 (ם), $0.15(\diamond), 0.10(\bullet)$ and $0.05(\boldsymbol{\Delta}) \mathrm{mg} \mathrm{SDS} \mathrm{g}^{-1}$ soil.

As it can be observed, the lower the SDS/soil ratio, the higher was the resulting concentration of lindane and the lower the concentration of SDS contained in the raw soil washing waste. However, despite this variation in the concentration, results point out that lindane can be exhausted in the four wastewaters electrolyzed, with required charges as low as $15 \mathrm{Ah} \mathrm{L}^{-1}$ in the case of the effluent obtained at $0.20 \mathrm{mg} \mathrm{g}^{-1}$, which needs to be increased up to $80 \mathrm{Ah} \mathrm{L}^{-1}$ for the complete removal of lindane in the effluent obtained 
with a ratio $0.05 \mathrm{mg} \mathrm{g}^{-1}$. In every case, intermediate is depleted before this point and the lack of other intermediate species (in GC ECD detectable concentrations) again points out the harsh oxidation conditions generated in the electrolyte during the electrolysis with diamond anodes, which favor the almost direct mineralization of the pollutant molecules contained in the waste. This observation is consistent with previous observations made in the electrolysis of other effluents polluted with a wide variety of pollutants $[45,46]$.

A very interesting point to be remarked in the Figure is the variation of the TOC. As it was pointed out before, this TOC can be almost exclusively associated to the surfactant SDS added during the SASW process. This concentration decreases during the four electrolysis, indicating the subsequent oxidation of the SDS molecule. However, when the lindane is completely depleted, very high concentrations of SDS still remain in the waste (over $70 \%$ of the initial concentration) and no other intermediate is present in detectable concentrations. This means that the treated effluent can be reused again for the SASW process minimizing the production of wastes.

It is interesting to see also how the micelles formed decreased in size from the initial value in which they are contained in the SASW effluent down to the mean size of soil particles, giving very relevant mechanistic information about the electrochemical oxidation, as they clearly point out how the micelles are attacked and reduced in size progressively. This information is presented in Figure 7. Due to the huge size of the micelles, this phenomenon can only take part in the bulk and, in addition, it may be only caused by oxidants reagents produced on the surface of the electrodes [47]. Likewise, taking into account the changes in the concentration of TOC and the evolution in the size of the micelles, once the micelles are completely destroyed, SDS should remain in solution as a soluble species. 


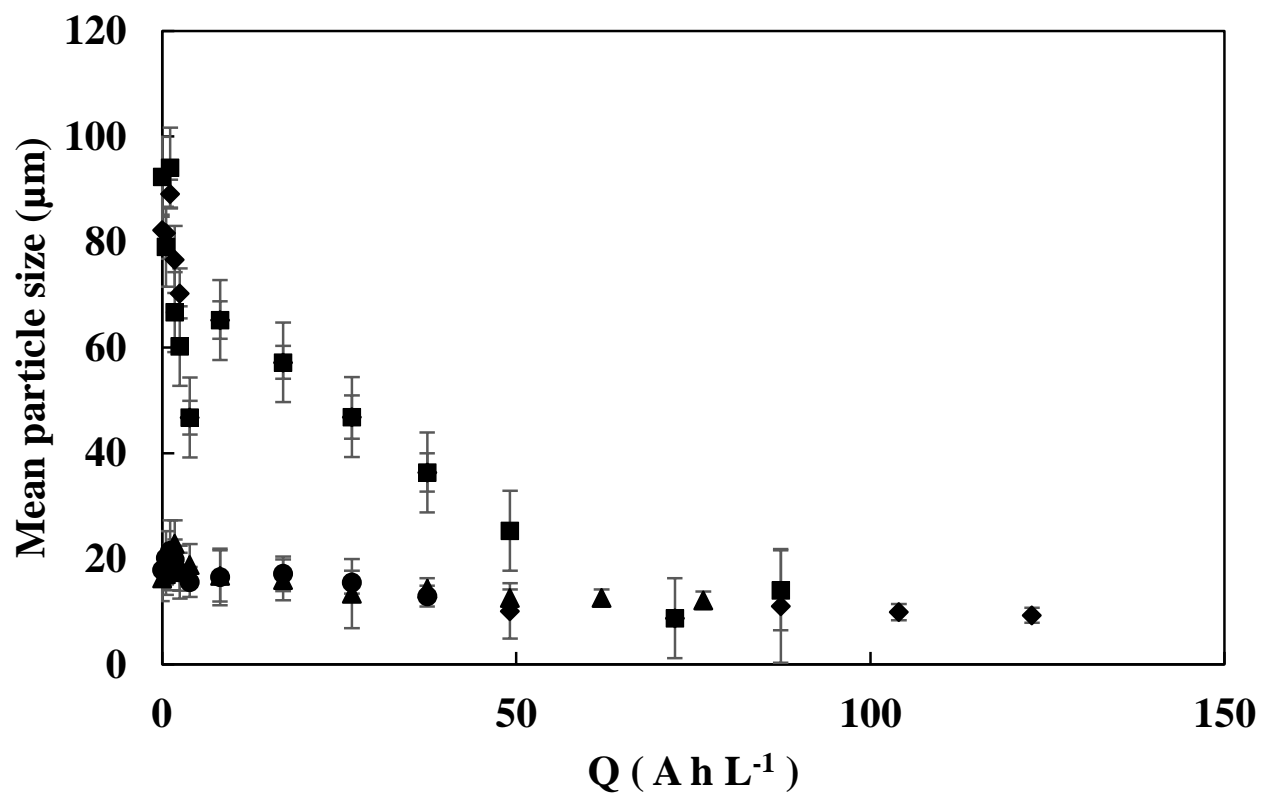

Figure 7. Changes in the mean particle size (and limits 10\%-90\%) observed during the electrolysis of soil washing effluents carried out at $0.20(\square), 0.15(\diamond), 0.10(\bullet)$ and 0.05 ( $\mathbf{\Delta}) \mathrm{mg} \mathrm{SDS} \mathrm{g}^{-1}$ soil.

A last important point is the variation in inorganic species during the electrolyses. In particular two parameters are of interest: sulfate ion and $\mathrm{pH}$ and the trends are shown in Figure 8. As it can be observed in part a of Figure 8, there is a growing concentration of sulfate in the treated SASW waste, which can be explained in terms of the release of this ion from the molecules of SDS during the electrochemically assisted oxidation of these molecules. 

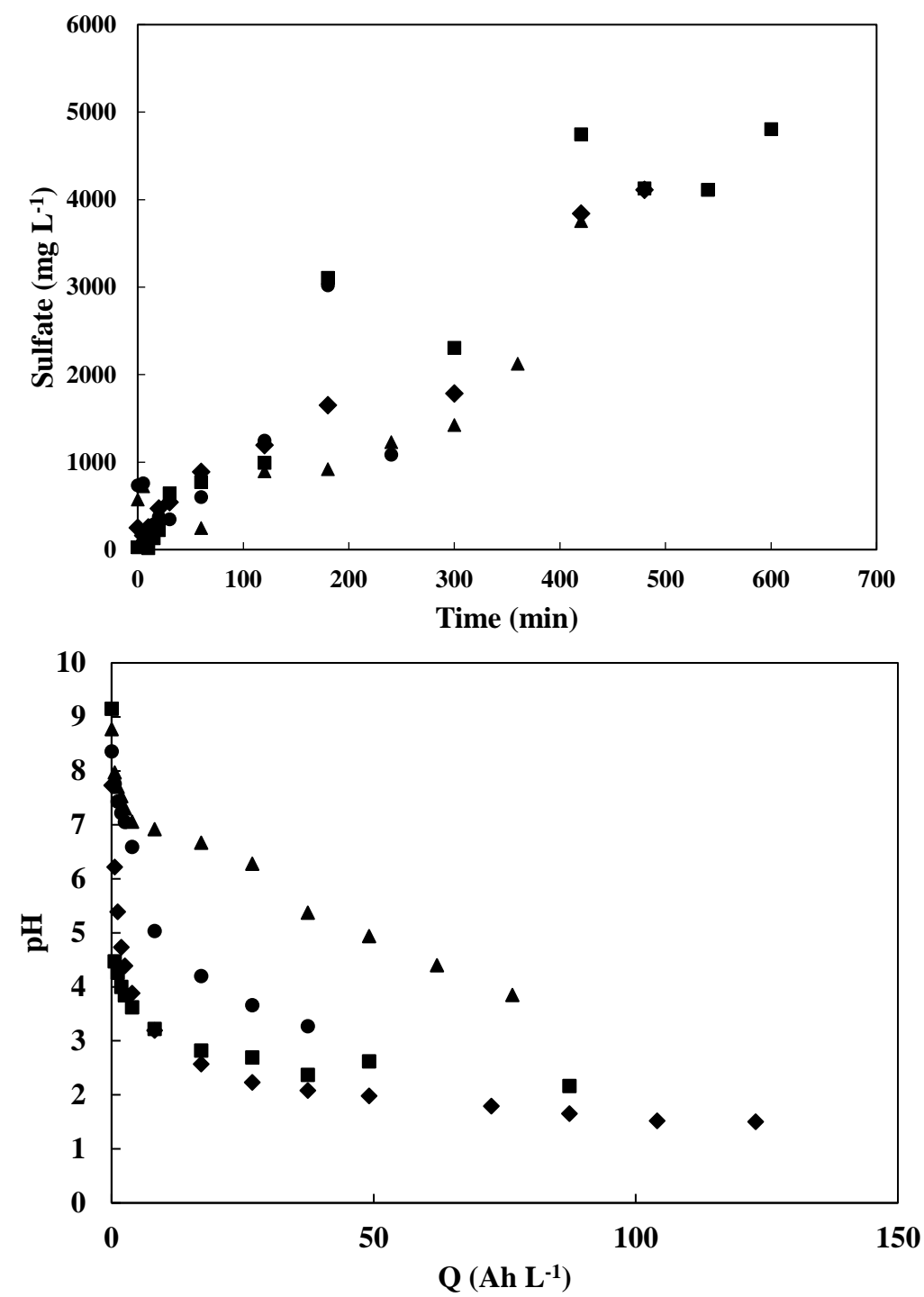

Figure 8. Production of sulfate (part a) and changes in $\mathrm{pH}$ and conductivity (part b) during the electrolysis of soil washing effluents carried out at $0.20(\boldsymbol{\square}), 0.15(\bullet), 0.10(\bullet)$ and $0.05(\mathbf{\Delta}) \mathrm{mg} \mathrm{SDS} \mathrm{g}{ }^{-1}$ soil

The concentrations released do not seem to depend on the initial concentration of SDS in the raw effluent but, opposite, it seems to be produced almost at a constants rate. In comparing this change with the changes observed in the TOC (plotted in Figure 5 semilogarithmic graph in order to allow see a constant oxidation rate), it may be concluded that the oxidation of the SDS takes part at a constant rate and that opposite to it was pointed out for oxyfluorfen and atrazine, the increasing presence of sulfate does not have 
an appreciable influence on the rate of the process (the rate remains constant during the complete duration of the tests)[11-13]. In the degradation of oxyfluorfen and atrazine, it was observed that the increasing presence of sulfate could be correlated with the increasing ratio in the degradation of organics, and it was explained in terms of the formation and performance of peroxodisulfates. Differences observed here point out that this oxidant is not as efficient in the degradation of lindane as it was in the degradation of oxyfluorfen.

A last important piece of information about the electrolyses can be obtained by comparing the variation of the $\mathrm{pH}$ values in the four wastes tested. The $\mathrm{pH}$ becomes acidic during the electrolysis, which is not a good news because it means that in a real application a neutralization operation could be required. In comparting the four effluents tested, it seems clear that the variation becomes much slower when the ratio SDS/soil decreases and this lower decrease has to be explained in terms of the buffering effect of the salts extracted from soil during the first SASW process.

\section{Conclusions}

From this work, the following conclusions can be drawn:

- Lindane can be efficiently removed from spiked soils by SASW. Characteristics of the effluents of this process largely depends on the SDS/soil ratio. As the SDS/soil ratio increases, so does the TOC and the mean size of the micelles.

- Effluents of the SASW process can be effectively mineralized by electrolysis with diamond anodes. Oxidation of lindane is very rapid and only one intermediate was detected by GC ECD and it was removed fast. On the contrary, SDS is removed more slowly with the release of sulfate ions but concentrations after the depletion 
of lindane are still high enough (more than 70\%) to regenerate the SWF for further use.

\section{Acknowledgements}

Financial support from the Spanish Ministry of Economy, Industry and Competitiveness and European Union through project CTM2016-76197-R (AEI/FEDER, UE) is gratefully acknowledged.

\section{References cited}

[1] E. Bocos, M.d.C. Fernandez Alonso, M. Pazos, D.M. Asuncion Longo Gonzalez, M. Angeles Sanroman, In situ soil remediation by electrokinetic-Fenton-like: Application to degradation of different emerging pollutants, Abstracts of Papers of the American Chemical Society, 248 (2014).

[2] H.I. Gomes, C. Dias-Ferreira, A.B. Ribeiro, Electrokinetic remediation of organochlorines in soil: Enhancement techniques and integration with other remediation technologies, Chemosphere, 87 (2012) 1077-1090.

[3] J. Virkutyte, M. Sillanpaa, P. Latostenmaa, Electrokinetic soil remediation - critical overview, Science of the Total Environment, 289 (2002) 97-121.

[4] M.A. Rodrigo, N. Oturan, M.A. Oturan, Electrochemically Assisted Remediation of Pesticides in Soils and Water: A Review, Chemical Reviews, 114 (2014) 8720-8745.

[5] A.B. Ribeiro, J.M. Rodriguez-Maroto, E.P. Mateus, H. Gomes, Removal of organic contaminants from soils by an electrokinetic process: the case of atrazine. Experimental and modeling, Chemosphere, 59 (2005) 1229-1239.

[6] A.B. Ribeiro, E.P. Mateus, J.-M. Rodriguez-Maroto, Removal of organic contaminants from soils by an electrokinetic process: The case of molinate and bentazone. Experimental and modeling, Separation and Purification Technology, 79 (2011) 193-203.

[7] D. Huguenot, E. Mousset, E.D. van Hullebusch, M.A. Oturan, Combination of surfactant enhanced soil washing and electro-Fenton process for the treatment of soils contaminated by petroleum hydrocarbons, Journal of Environmental Management, 153 (2015) 40-47.

[8] E. Mousset, N. Oturan, E.D. van Hullebusch, G. Guibaud, G. Esposito, M.A. Oturan, Influence of solubilizing agents (cyclodextrin or surfactant) on phenanthrene degradation by electro-

Fenton process - Study of soil washing recycling possibilities and environmental impact, Water Research, 48 (2014) 306-316.

[9] E. Mousset, N. Oturan, E.D. van Hullebusch, G. Guibaud, G. Esposito, M.A. Oturan, Treatment of synthetic soil washing solutions containing phenanthrene and cyclodextrin by electro-oxidation. Influence of anode materials on toxicity removal and biodegradability enhancement, Applied Catalysis B-Environmental, 160 (2014) 666-675. 
[10] C. Trellu, O. Ganzenko, S. Papirio, Y. Pechaud, N. Oturan, D. Huguenot, E.D. van Hullebusch, G. Esposito, M.A. Oturan, Combination of anodic oxidation and biological treatment for the removal of phenanthrene and Tween 80 from soil washing solution, Chemical Engineering Journal, 306 (2016) 588-596.

[11] E.V. dos Santos, C. Saez, C.A. Martinez-Huitle, P. Canizares, M.A. Rodrigo, Combined soil washing and CDEO for the removal of atrazine from soils, Journal of Hazardous Materials, 300 (2015) 129-134.

[12] E.V. dos Santos, C. Saez, C.A. Martinez-Huitle, P. Canizares, M.A. Rodrigo, The role of particle size on the conductive diamond electrochemical oxidation of soil-washing effluent polluted with atrazine, Electrochemistry Communications, 55 (2015) 26-29.

[13] E.V. dos Santos, C. Saez, C.A. Martinez-Huitle, P. Canizares, M. Andres Rodrigo, Removal of oxyfluorfen from ex-situ soil washing fluids using electrolysis with diamond anodes, Journal of Environmental Management, 171 (2016) 260-266.

[14] E.V. dos Santos, C. Sáez, P. Cañizares, D.R. da Silva, C.A. Martínez-Huitle, M.A. Rodrigo, Treatment of ex-situ soil-washing fluids polluted with petroleum by anodic oxidation, photolysis, sonolysis and combined approaches, Chemical Engineering Journal, 310, Part 2 (2017) 581-588.

[15] F.L. Souza, C. Saez, M.R.V. Lanza, P. Canizares, M.A. Rodrigo, Removal of pesticide 2,4-D by conductive-diamond photoelectrochemical oxidation, Applied Catalysis B-Environmental, 180 (2016) 733-739.

[16] C. Saez, R. Lopez-Vizcaino, P. Canizares, M.A. Rodrigo, Conductive-Diamond Electrochemical Oxidation of Surfactant-Aided Soil-Washing Effluents, Industrial \& Engineering Chemistry Research, 49 (2010) 9631-9635.

[17] R.J. Flaherty, B. Nshime, M. DeLaMarre, S. DeJong, P. Scott, A.W. Lantz, Cyclodextrins as complexation and extraction agents for pesticides from contaminated soil, Chemosphere, 91 (2013) 912-920.

[18] J. Gomez, M. Teresa Alcantara, M. Pazos, M. Angeles Sanroman, Soil washing using cyclodextrins and their recovery by application of electrochemical technology, Chemical Engineering Journal, 159 (2010) 53-57.

[19] J.F. Lee, M.H. Hsu, H.P. Chao, H.C. Huang, S.P. Wang, The effect of surfactants on the distribution of organic compounds in the soil solid/water system, Journal of Hazardous Materials, 114 (2004) 123-130.

[20] R. Semer, K.R. Reddy, Evaluation of soil washing process to remove mixed contaminants from a sandy loam, Journal of Hazardous Materials, 45 (1996) 45-57.

[21] E. Mousset, M.A. Oturan, E.D. Van Hullebusch, G. Guibaud, G. Esposito, Soil

Washing/Flushing Treatments of Organic Pollutants Enhanced by Cyclodextrins and Integrated Treatments: State of the Art, Critical Reviews in Environmental Science and Technology, 44 (2014) 705-795.

[22] F. Pardo, A. Santos, A. Romero, Fate of iron and polycyclic aromatic hydrocarbons during the remediation of a contaminated soil using iron-activated persulfate: A column study, Science of the Total Environment, 566 (2016) 480-488.

[23] I. Sires, E. Brillas, M.A. Oturan, M.A. Rodrigo, M. Panizza, Electrochemical advanced oxidation processes: today and tomorrow. A review, Environmental Science and Pollution Research, 21 (2014) 8336-8367.

[24] C.A. Martínez-Huitle, M.A. Rodrigo, I. Sirés, O. Scialdone, Single and Coupled Electrochemical Processes and Reactors for the Abatement of Organic Water Pollutants: A Critical Review, Chemical Reviews, 115 (2015) 13362-13407.

[25] P.C. Abhilash, B. Singh, P. Srivastava, A. Schaeffer, N. Singh, Remediation of lindane by Jatropha curcas L: Utilization of multipurpose species for rhizoremediation, Biomass \& Bioenergy, 51 (2013) 189-193. 
[26] R. Calvelo Pereira, M.C. Monterroso Martinez, A. Martinez Cortizas, F. Macias, Analysis of composition, distribution and origin of hexachlorocyclohexane residues in agricultural soils from NW Spain, Science of the Total Environment, 408 (2010) 5583-5591.

[27] J. Fernandez, M.A. Arjol, C. Cacho, POP-contaminated sites from HCH production in Sabinanigo, Spain, Environmental Science and Pollution Research, 20 (2013) 1937-1950.

[28] T.M. Phillips, A.G. Seech, H. Lee, J.T. Trevors, Biodegradation of hexachlorocyclohexane $(\mathrm{HCH})$ by microorganisms, Biodegradation, 16 (2005) 363-392.

[29] A.M. Nienow, J.C. Bezares-Cruz, I.C. Poyer, I. Hua, C.T. Jafvert, Hydrogen peroxide-assisted UV photodegradation of Lindane, Chemosphere, 72 (2008) 1700-1705.

[30] S. Waclawek, V. Antos, P. Hrabak, M. Cernik, Remediation of hexachlorocyclohexanes by cobalt-mediated activation of peroxymonosulfate, Desalination and Water Treatment, 57 (2016) 26274-26279.

[31] C.M. Dominguez, S. Rodriguez, D. Lorenzo, A. Romero, A. Santos, Degradation of Hexachlorocyclohexanes (HCHs) by Stable Zero Valent Iron (ZVI) Microparticles, Water Air and Soil Pollution, 227 (2016).

[32] C.M. Dominguez, J. Parchao, S. Rodriguez, D. Lorenzo, A. Romero, A. Santos, Kinetics of Lindane Dechlorination by Zerovalent Iron Microparticles: Effect of Different Salts and Stability Study, Industrial \& Engineering Chemistry Research, 55 (2016) 12776-12785.

[33] A. Matsunaga, A. Yasuhara, Dechlorination of polychlorinated organic compounds by electrochemical reduction with naphthalene radical anion as mediator, Chemosphere, 59 (2005) 1487-1496.

[34] J.P. Merz, B.C. Gamoke, M.P. Foley, K. Raghavachari, D.G. Peters, Electrochemical reduction of $(1 \mathrm{R}, 2 \mathrm{r}, 3 \mathrm{~S}, 4 \mathrm{R}, 5 \mathrm{r}, 6 \mathrm{~S})$-hexachlorocyclohexane (Lindane) at carbon cathodes in dimethylformamide, Journal of Electroanalytical Chemistry, 660 (2011) 121-126.

[35] A.A. Peverly, J.A. Karty, D.G. Peters, Electrochemical reduction of $(1 R, 2 r, 3 S, 4 R, 5 r, 6 S)$ hexachlorocyclohexane (Lindane) at silver cathodes in organic and aqueous-organic media, Journal of Electroanalytical Chemistry, 692 (2013) 66-71.

[36] W. Zhu, C. Ni, L. Liang, J. Li, M. Li, Z. Ou, K.M. Kadish, Electroreductive dechlorination of alpha-hexachlorocyclohexane catalyzed by iron porphyrins in nonaqueous media, Journal of Porphyrins and Phthalocyanines, 18 (2014) 519-527.

[37] J. Bringmann, K. Ebert, U. Galla, H. Schmieder, ELECTROCHEMICAL MEDIATORS FOR TOTAL OXIDATION OF CHLORINATED HYDROCARBONS - FORMATION KINETICS OF AG(II), CO(III), AND CE(IV), Journal of Applied Electrochemistry, 25 (1995) 846-851.

[38] F.A. Beland, S.O. Farwell, A.E. Robocker, R.D. Geer, ELECTROCHEMICAL REDUCTION AND ANAEROBIC DEGRADATION OF LINDANE, Journal of Agricultural and Food Chemistry, 24 (1976) 753-756.

[39] E. Jurado, M. Fernandez-Serrano, J. Nunez-Olea, G. Luzon, M. Lechuga, Simplified spectrophotometric method using methylene blue for determining anionic surfactants: Applications to the study of primary biodegradation in aerobic screening tests, Chemosphere, 65 (2006) 278-285.

[40] F. Souza, S. Quijorna, M.R.V. Lanza, C. Saez, P. Canizares, M.A. Rodrigo, Applicability of electrochemical oxidation using diamond anodes to the treatment of a sulfonylurea herbicide, Catalysis Today, 280 (2017) 192-198.

[41] C. Trellu, E. Mousset, Y. Pechaud, D. Huguenot, E.D. van Hullebusch, G. Esposito, M.A. Oturan, Removal of hydrophobic organic pollutants from soil washing/flushing solutions: A critical review, Journal of Hazardous Materials, 306 (2016) 149-174.

[42] R.D. Villa, A.G. Trovo, R.F. Pupo Nogueira, Soil remediation using a coupled process: soil washing with surfactant followed by photo-Fenton oxidation, Journal of Hazardous Materials, 174 (2010) 770-775.

[43] K. Chair, A. Bedoui, N. Bensalah, F.J. Fernandez-Morales, C. Saez, P. Canizares, M.A. Rodrigo, Combining bioadsorption and photoelectrochemical oxidation for the treatment of 
soil-washing effluents polluted with herbicide 2,4-D, Journal of Chemical Technology and Biotechnology, 92 (2017) 83-89.

[44] R. Lopez-Vizcaino, C. Saez, P. Canizares, M.A. Rodrigo, The use of a combined process of surfactant-aided soil washing and coagulation for PAH-contaminated soils treatment, Separation and Purification Technology, 88 (2012) 46-51.

[45] I. Sirés, E. Brillas, M.A. Oturan, M.A. Rodrigo, M. Panizza, Electrochemical advanced oxidation processes: today and tomorrow. A review, Environmental Science and Pollution Research, (2014).

[46] C.A. Martinez-Huitle, M.A. Rodrigo, I. Sires, O. Scialdone, Single and Coupled Electrochemical Processes and Reactors for the Abatement of Organic Water Pollutants: A Critical Review, Chemical Reviews, 115 (2015) 13362-13407.

[47] P. Canizares, C. Saez, A. Sanchez-Carretero, M.A. Rodrigo, Synthesis of novel oxidants by electrochemical technology, Journal of Applied Electrochemistry, 39 (2009) 2143-2149. 